\section{QUE YO LAS NUBES RESISTIR NO PUEDO: LAS RESPUESTAS DE CAROLINA CORONADO Y LUISA PÉREZ DE ZAMBRANA ANTE LA POLÉMICA EN TORNO AL GÉNERO EN GERTRUDIS GÓMEZ DE AVELLANEDA (UNA LECTURA TRANSATLÁNTICA)}

\author{
Milena Rodríguez Gutiérrez \\ Universidad de Granada \\ milena@ugr.es
}

\section{QUE YO LAS NUBES RESISTIR NO PUEDO: THE ANSWERS OF CAROLINA CORONADO AND LUISA PÉREZ DE ZAMBRANA TO THE GENDER POLEMIC IN GERTRUDIS GÓMEZ DE AVELLANEDA (A TRANSATLANTIC READING)}

Copyright: (C) 2014 CSIC. Este es un artículo de acceso abierto distribuido bajo los términos de la licencia Creative Commons Attribution-Non Commercial (by-nc) Spain 3.0. Carolina Coronado y Luisa Pérez de Zambrana ante la polémica en torno al género en Gertrudis Gómez de Avellaneda (Una lectura transatlántica)". Arbor, 190 (770): a183. doi: http:// dx.doi.org/10.3989/arbor.2014.770n6004

Recibido: 12 febrero 2014. Aceptado: 30 octubre 2014.

RESUMEN: Este artículo propone un acercamiento a la llamada "polémica en torno al género" en Gertrudis Gómez de Avellaneda desde una perspectiva transatlántica. Se consideran, de modo simultáneo, los principales críticos españoles y cubanos que intervienen en este debate. Pero fundamentalmente se pretende escuchar a las dos escritoras que en España y en Cuba desempeñaron similar función, Carolina Coronado y Luisa Pérez; ubicadas, en los dos países, en sitios parecidos: como poetisas y contrincantes femeninas de Avellaneda, quien fue considerada poeta, en el sentido masculino del término. Nuestro trabajo propone indagar en diversas cuestiones relacionadas con Coronado y Pérez: qué había en común entre ambas autoras; cuál fue su juicio sobre Avellaneda; cuáles fueron sus respuestas ante la polémica. La hipótesis propuesta es que la lectura comparada de las respuestas de Coronado y Pérez contribuirá a enriquecer el conocimiento en torno a esta polémica.

PALABRAS CLAVE: Gertrudis Gómez de Avellaneda; Carolina Coronado; Luisa Pérez de Zambrana; poesía; estudios de género; estudios transatlánticos; polémica; feminismo.
ABSTRACT: This paper offers an approach to the "gender polemic" in Gertrudis Gomez de Avellaneda from a transatlantic perspective. We simultaneously consider the main Spanish and Cuban critics involved in the controversy. But fundamentally we aim to hear how the two women writers in Spain and Cuba played a similar function: Carolina Coronado and Luisa Perez placed, in the two countries, in similar sites, as feminine opponents of Avellaneda, who was viewed as a male poet. Our study aims to look into various issues related to Coronado and Perez: what the two women authors had in common, their opinion of Avellaneda, and their responses to the controversy. The proposed hypothesis is that the comparative reading of the Coronado's and Perez's responses will contribute to deepening our understanding of this controversy.

KEYWORDS: Gertrudis Gómez de Avellaneda; Carolina Coronado; Luisa Perez de Zambrana; poetry; gender studies; transatlantic studies; controversy; feminism. 


\section{UNA POLÉMICA TRANSATLÁNTICA O “LA NUBE AMENAZANTE"}

En 1846 Antonio Ferrer del Río publicó en Madrid su Galería de la literatura española. Entre los escritores del volumen solo fue incluida una mujer, Gertrudis Gómez de Avellaneda, cuyo nombre aparecía, sin embargo, sintomáticamente tachado, pues encima de este el galerista superponía el de otra escritora, Carolina Coronado. La tachadura de Avellaneda se debía, según el estudioso, a que la autora, más que poetisa, era poeta. El párrafo de Ferrer del Río, al que la crítica posterior ha aludido en numerosas ocasiones pero que pocas veces se reproduce, decía lo siguiente:

Señorita Doña Gertrudis Gómez de Avellaneda. Al frente de las poetisas españolas se encuentra la Carolina Coronado: no es la Avellaneda poetisa, sino poeta: sus atrevidas concepciones, su elevado tono, sus acentos valientes, son impropios de su sexo. Escribe odas y tragedias: como novelista luce más en Espatolino y en Guatimocin que en Sab y las Dos Mujeres. Ha alcanzado triunfos escénicos en Alfonso Munio y el Príncipe de Viana: en un solo certamen ha merecido dos premios: de Saúl, tragedia bíblica, nos han contado maravillas. Corresponde la altivez y soberbia de su carácter al mérito de sus composiciones: su vida tendría muchos puntos de contacto con la de Jorge Sand si la sociedad madrileña se asemejase en todo á la sociedad parisiense (Ferrer del Río, 1846, p. 309).

No era la primera vez que la crítica española emitía un juicio similar. Numerosos críticos, estudiosos, escritores de la época, dijeron palabras parecidas; como bien dice María Prado Más, "la autora española a la que más se trasvistió en España fue sin duda ninguna Gertrudis Gómez de Avellaneda" (Prado Más, 2001, p. 53). Ya en el prólogo a la primera edición de la poesía de Gómez de Avellaneda, publicada en 1841, Juan Nicasio Gallego escribía: "Todo en sus cantos es nervioso y varonil: así cuesta trabajo persuadirse que no son obra de un escritor del otro sexo. No brillan tanto en ellos los movimientos de ternura, ni las formas blandas y delicadas, propias de un pecho femenil y de la dulce languidez que infunde en sus hijos el sol ardiente de los trópicos, que alumbró su cuna" (Gómez de Avellaneda, 1841, p. IX).

Casi treinta años después de Ferrer del Río, en 1875 y apenas dos años más tarde de la muerte de Gertrudis Gómez de Avellaneda, José Martí actualiza, para Cuba y para América Latina, el juicio español sobre el sexo de Avellaneda, llevando a cabo en la Revista Universal de México una operación similar de borradura de la escritora, aunque más sofisticada y de consecuencias más profundas. Al comentar la antología Poetisas americanas de José Domingo Cortés, publicada en esas fechas en París, Martí tacha el nombre de Avellaneda no solo como mujer, sino también como (supuesto) símbolo de las "poetisas de América". En ambos lugares coloca el nombre de otra cubana, Luisa Pérez de Zambrana, quien sí poseía, a diferencia de Avellaneda y según Martí, "un alma clara de mujer". Los motivos martianos son, aparentemente, parecidos a los de la crítica española; y Martí se regodea en ellos. Describe en su artículo a Luisa Pérez, "pura criatura, a toda pena sensible y habituada a toda delicadeza y generosidad", quien, como "mujer de un hombre ilustre [...] entiende que el matrimonio con el esposo muerto dura tanto como la vida de la esposa fiel" (Martí, $1875 / 1977$, p. 135). No lo dice con todas sus letras, pero sus palabras suponen un tácito reproche a Avellaneda quien, a diferencia de Luisa Pérez -viuda desde muy joven y durante toda su vida del médico y escritor Ramón Zambrana-, contrajo nuevamente matrimonio con Domingo Verdugo después de la muerte de su primer marido, Pedro Sabater. Más adelante, la comparación se hace explícita y la figura de Avellaneda y sus versos quedan despojados, si no de talento, sí de feminidad, y como consecuencia de esta carencia, de toda posibilidad de representar a las escritoras americanas:

Hay un hombre altivo, a las veces fiero, en la poesía de la Avellaneda: hay en todos los versos de Luisa [Pérez de Zambrana] un alma clara de mujer. Se hacen versos de la grandeza pero solo del sentimiento se hace poesía. La Avellaneda es atrevidamente grande. Luisa Pérez es tiernamente tímida.

Ha de preguntarse, a más, no solamente cuál es entre las dos la mejor poetisa, sino cuál de ellas es la mejor poetisa americana. $Y$ en esto, nos parece que no ha de haber vacilación.

No hay mujer en Gertrudis Gómez de Avellaneda: todo anunciaba en ella un ánimo potente y varonil; era su cuerpo alto y robusto, como su poesía ruda y enérgica; no tuvieron las ternuras miradas para sus ojos, llenos siempre de extraño fulgor y de dominio: era algo así como una nube amenazante. Luisa Pérez es algo como nube de nácar y azul en tarde serena y bonancible. Sus dolores son lágrimas: los de Avellaneda son fiereza. Más: la Avellaneda no sintió el dolor humano: era más alta y más potente que él; su pesar era una roca; el de Luisa Pérez, una flor. Violeta casta, nelumbio quejumbroso, pasionaria triste. 
¿A quién escogerías por tu poetisa, oh apasionada y cariñosa naturaleza americana?

\section{Una hace temer; otra hace llorar. [...]}

Lo plácido y lo altivo: alma de hombre y alma de mujer; rosa erguida y nelumbio quejumbroso; idelicadísimo nelumbio! (Martí, 1875/1977, p. 136).

Excelentes trabajos de estudiosas contemporáneas, entre los que quizá merecen destacarse los de Susan Kirkpatrick (1991), Mary Louise Pratt (2003) o Nuria Girona (2011), se han acercado a esta cuestión de la masculinización de Avellaneda por parte de la crítica y a los reproches y descalificaciones sexistas que sufrió su figura y su obra en el XIX y aún en el XX, tanto en España como en Cuba. Algunas han cuestionado además frontalmente el punto de vista martiano sobre la escritora: "el radicalismo democratizante de Martí no se extendía al orden de género", escribe rotunda Pratt (Pratt, 2003, p. 36). Kirkpatrick, por su parte, en su imprescindible Las Románticas, lee las obras poéticas de Avellaneda y Coronado y establece relaciones entre la escritura de ambas y sus posiciones subjetivas. La puesta en relación de Avellaneda y Luisa Pérez ha sido también esbozada, fundamentalmente en los trabajos de estudiosas cubanas, como los de Madeline Cámara (1998) o Susana Montero (2003). Falta, sin embargo, desde mi punto de vista, una lectura de conjunto de esta que podríamos nombrar "polémica en torno al género en Avellaneda" (con ciertas reservas, sin duda: ¿puede llamarse verdaderamente polémica a un ataque en el que hay casi una única opinión, a una pelea en la que todos los intervinientes pegan del mismo lado mientras el espacio de enfrente permanece prácticamente vacío?); falta enfocar esta polémica desde una perspectiva que acaso vale llamar transatlántica, pues se trataría de tomar en consideración, de modo simultáneo, a los críticos españoles y cubanos; y aún más que a estos, que ya han sido muy escuchados, a esas dos escritoras que en España y en Cuba desempeñaron similar función, esas dos poetisas, Carolina Coronado y Luisa Pérez, que fueron colocadas en el mismo sitio, como contrincantes femeninas de Avellaneda. ¿Qué había en común entre ellas?, ¿cuáles fueron sus respuestas ante la polémica y qué significación tuvo para ambas? ¿Qué dijeron cada una sobre Avellaneda? ¿Es posible que sus respuestas, sus palabras, leídas una junto a la otra, añadan algo a lo que ya conocemos en torno a este tema? Propongo en estas páginas un acercamiento desde esta perspectiva.

\section{ESPAÑA Y CAROLINA CORONADO}

No hay cartas o documentos que prueben la existencia de relaciones de amistad entre Carolina Coronado y Gertrudis Gómez de Avellaneda (Fernández Daza, 2012, p. 3). Sí se encuentran, sin embargo, evidencias de la admiración de la extremeña hacia la cubana: una carta a Hartzenbusch escrita en 1848, donde habla de un retrato de Avellaneda encargado un año atrás y que por fin acaba de recibir (cit. en Fernández Daza, 2012, p. 290); carta donde se recoge un comentario de sorpresa de Coronado ante la belleza de la retratada, que denota que hasta esa fecha no se han conocido personalmente.

Será en dos artículos publicados entre 1857 y 1858 en el periódico español La Discusión, donde Carolina Coronado ofrezca su respuesta a la opinión de Ferrer del Río sobre Gertrudis Gómez de Avellaneda. En la sección "Galería de poetisas contemporáneas", Coronado dedicó a Avellaneda dos artículos muy interesantes, que volvieron a publicarse en 1861 en la revista madrileña La América. Coronado se refiere al volumen de Ferrer del Río, aunque nunca dice, quizás por modestia, o tal vez por vergüenza, que en aquel volumen era su nombre el que aparecía tachando el de Avellaneda. Es conocido cómo Coronado atribuye al éxito de la escritora la masculinización de su figura: "Los otros hombres del tiempo antiguo negaban el genio de la mujer; hoy los del moderno, ya que no pueden negar al que triunfa, le metamorfosean" (Coronado, 1861a, p. 10). Pero Coronado acepta también la existencia de dos facetas en Avellaneda: la de poetisa y la de poeta y va adscribiendo a dichas facetas diferentes textos poéticos de la escritora, sin dejar, sin embargo, por ello, de reclamar su lugar entre las mujeres: "Pues decidme, poetas, ¿tan pocos sois en la creadora España, donde son poetas los legisladores, poetas los diplomáticos, poetas los sacerdotes y poetas los guerreros que necesitáis aumentar vuestro número con el nombre de una mujer?" (Coronado, 1861a, p. 10), y reivindica, finalmente, la condición femenina de la escritora: "Un poeta festivo pudo exclamar al leer estas últimas composiciones: 'Es mucho hombre esta mujer'. Yo al leer las primeras, pensando en que han declarado hombre á su autora exclamo: ies mucha mujer este hombre!" (Coronado, 1861a, p. 11). Pero acaso la cuestión más importante aparece en el segundo de estos artículos, donde Coronado se refiere a la condición de autora teatral de Avellaneda, situando esta circunstancia como la más problemática para la aceptación de la feminidad de la cubana por parte de la sociedad y el mundo literario españoles. 
Coronado, que describe la que llama la "España francesa" como una mala copia de Francia, sitúa en ese espacio simbólico español el teatro que se hace en ese momento y escribe:

Yo no conozco los hábitos de la escritora, cuyas obras estudio respetuosamente; pero creo que el haber elegido el teatro para campo do sus glorias ha sido uno de los mayores inconvenientes con que ha tenido que luchar, el teatro está colocado aquí en la España francesa, y los franceses codiciosos que perdonarían á una mujer el que fuese atea, no la perdonarían el que ganase mil francos en un drama (Coronado, 1861b, p. 10).

Muy sagazmente Coronado pone el dedo sobre la llaga al referirse a un hecho en el que creo que aún no se ha insistido lo suficiente: que es con el teatro con el que Avellaneda se convierte realmente en una escritora profesional, que gana dinero y que puede vivir, como algunos escritores (no todos) de su trabajo. $\mathrm{Y}$, como bien afirma Coronado, esta circunstancia, si bien no provocó el trasvestismo que sufrió la escritora por parte de la crítica, pues como hemos dicho este existió desde que publicó su primer libro, sí creo que contribuyó notablemente a reforzarlo, a acentuarlo y a convertirlo en más intenso y/o virulento ${ }^{1}$. Una mujer con "habitación propia", que triunfa como autora y gana dinero con su trabajo, es, sin duda, mucho más peligrosa y supone una competencia mayor que una poetisa, por mucho que esta pretenda ser poeta y se acerque a temas varoniles y escriba sobre Francia, Napoleón o sobre la muerte de José María Heredia. Es, así, a partir del trabajo de Avellaneda como dramaturga que se verifican estas palabras que muy acertadamente ha apuntado Nuria Girona: [En Avellaneda] "el trabajo creativo se enfrenta profesionalmente y profesionalmente significa no solo en una intensa dedicación al mundo de las letras [...] sino en la disciplina con que se ejecuta [...] y por supuesto, en la retribución (efectiva y simbólica) que recompense esta actividad" (Girona, 2011, p. 166, énfasis de la autora).

Hay, más adelante, en el segundo artículo de Carolina Coronado, otra idea que también merece la pena destacarse y es la exhortación a las poetisas coetáneas a que respeten a la escritora, pero también a que no la tomen como modelo, precisamente por su condición de autora dramática:

[...] no la aceptéis como ejemplo; no debe ni puede servir de modelo para la educación literaria de las poetisas. Lejos de esforzar cada una su ánimo, en imitar ese gran fenómeno, debe reprimir sus aspiraciones ambiciosas. Si a pesar de todo, sin pretenderlo, sin desearlo [...] prorrumpe una de vosotras en acentos que conmueven, que arrebatan al público, y que arrancan de manos de los mismos enemigos de las poetisas laureles de triunfo, respetad á esa escritora. (Coronado, 1861b, p. 10).

Estas palabras de Coronado subrayan cómo Avellaneda se convierte en anti-modelo para las poetisas españolas de la época, sin duda por su propia poesía pero, sobre todo, por su condición de autora teatral de éxito. Carolina Coronado quizás pretende no desestimular la vocación poética entre las mujeres, y pone el acento en el rechazo a la vocación que ella cree realmente peligrosa para estas, la de dramaturga, una profesión que, como ella misma describe en su artículo, resulta bien difícil de asumir para una mujer:

La profesión de poeta dramático es dura aun para los hombres mismos. La poesía lírica no necesita mas que genio y soledad: el arte dramático necesita ademas mecanismo. No le basta á la poetisa crear una obra, es preciso que la ponga en accion, y para esto se necesitan trabajos que verdaderamente no puede hacer una mujer sin grandes y peligrosos combates.

Todos los traductores de comedias han de ser sus enemigos, todos los escritores dramáticos sus rivales, todos los editores sus tiranos, todos los empresarios sus amigos, y todos los cómicos sus compañeros. La actividad, la energía, el vigor que la autora necesita desplegar para que su obra tenga éxito, la hacen olvidar que es mujer; tiene que pasar largas horas entre bastidores, animando a unos, reprendiendo á otros, y cuando llega la noche del estreno, necesita ser un héroe para sufrir el tenor de una silva, ó varón para soportar los aplausos, presentándose en escena ante el público arrebatado. (Coronado, 1861b, p. 10).

Las palabras de Coronado contribuyen a acentuar el mérito de Avellaneda al convertirse en autora dramática y nos ofrecen elementos para comprender mejor las dificultades que tuvieron que afrontar las mujeres en España para acceder al más público de los géneros literarios. Pero, ¿podemos considerar estos artículos, de modo exclusivo, como la respuesta de Carolina Coronado a esta polémica? Cabe, me parece, examinar también la propia escritura poética de Coronado. Aquí habría que mencionar un poema dedicado a Avellaneda, fechado en 1846 e incluido en el cuaderno que Coronado tituló "A las poetisas". Bajo el sugestivo título de "Yo no puedo seguirte con mi vuelo", en este texto poético queda patente su admiración hacia Avellaneda, aunque también sus reservas ante la elección de la cubana. 
El poema comienza poniendo de manifiesto las supuestas diferencias, el contraste entre ambas: una, Avellaneda, es de "villa populosa" y "acacia de jardín"; la otra, Coronado, es "zarza campesina", "vecina de valle pacífico"; es decir, Coronado se asocia a sí misma con la naturaleza, mientras identifica a Avellaneda con la ciudad. Por otra parte, Avellaneda será "viajera golondrina", mientras la voz poética se considera a sí misma "tortuga perezosa". A pesar de las diferencias, las escritoras parecen ir juntas en su ruta, pero se trata de una circunstancia que ha de cambiar pronto, precisamente por el ascenso que va experimentando la cubana:

$$
\begin{aligned}
& \text { El entusiasmo que hacia ti me impele, } \\
& \text { la dulce fe que hacia mi amor te guía, } \\
& \text { disponen que en amiga compañía, } \\
& \text { mi canto unido a tus acentos vuele; } \\
& \text { mas yo no sé, paloma, si recele } \\
& \text { que, al fin, he de quedar sola en la vía, } \\
& \text { pues tal vas ascendiendo por el cielo, } \\
& \text { que no puedo seguirte con mi vuelo } \\
& \text { (Coronado, 1991, p. 523). }
\end{aligned}
$$

Más adelante encontramos en el poema el llamado topos de la "falsa disculpa" que suele aparecer en la escritura de mujeres; esa "declaración de autodescalificación" (Russotto, 1993, p. 77), literal, aunque con cierto carácter irónico en este caso, que se irá revelando a lo largo del texto: la escritura de Avellaneda, su voz, emerge desde la regia villa -y adviértase aquí la polisemia del término, que tanto puede referirse a la magnificencia de la ciudad, como a la corte, al palacio real que efectivamente frecuentó la cubana-, mientras la voz de Coronado solo puede "modular" canciones -es decir, ni siquiera consigue llegar a cantarlas-, en homenaje a cosas insignificantes, menores, como esas florecillas, que aún parecen menos significativas gracias al diminutivo con que la voz poética las designa: "Tú desde el centro de la regia villa / domeñas con la voz los corazones, / yo solo alcanzo a modular canciones / en honor de la simple florecilla". (Coronado, 1991, pp. 523-524).

Las alusiones a la distancia que crece entre ambas mujeres continúan en la siguiente estrofa, donde la voz poética sigue presentándose como incapaz de soñar con un triunfo como el de Avellaneda, asumiendo también para sí misma una actitud en concordancia con las recomendaciones que daba a las escritoras en su artículo sobre Avellaneda: no envidiar a las mujeres que consiguen triunfar en las letras, respetar su obra y admirarlas:
Si mi ardoroso empeño a ti me envía,

de ti me aparta el genio que te eleva

y sola a conquistar la prez te lleva

que no osara tocar mi fantasía:

pero no temas, no, que el alma mía

de su destino a murmurar se atreva,

pues que suyo será el bello destino

de alfombrarte de flores el camino.

(Coronado, 1991, p. 524).

A partir de la quinta estrofa puede decirse, sin embargo, que en el poema se produce una fractura: se presenta en el texto, de improviso, la posibilidad de que la escritora que triunfa acabe descubriendo que la sociedad que ha elegido no es aquello que imaginaba y vuelva entonces la vista hacia esa naturaleza escogida por Coronado, naturaleza que parecía hasta ese momento menor y que de pronto adquiere, en el poema, mayor importancia e interés que la sociedad $y$, sin duda, mayor autenticidad:
Mas, al fijar la perspicaz mirada
en esa sociedad, cuya existencia
ha menester de intérprete a la ciencia
para ser comprendida y revelada;
afligida sintiendo y fatigada,
acaso tu sencilla inteligencia,
rechazarás el mundo con enojos
y hacia mi valle tornarás los ojos
(Coronado, 1991, p. 524).

La simplicidad, coherencia y bondad de la naturaleza es resaltada y elogiada en las estrofas siguientes: la garza que cría amorosamente a los polluelos, los canes que cuidan lealmente a la familia, la abeja que deja sus frutos a la colmena, se presentan como contrapunto a lo que ocurre en la sociedad de los humanos, criticada por la voz poética, con argumentos que nos recuerdan, de algún modo, los utilizados en otro poema de Coronado fechado en el mismo año, "Libertad", poema que constituye uno de los más duros que la autora escribiera contra la sociedad de su época y contra el liberalismo, del que fue partidaria, por la exclusión que sufrían las mujeres. Sin llegar a emitir un juicio tan intenso como el de "Libertad", los versos en que Coronado cuestiona la sociedad de su época, plantean también un rechazo que justifica el alejamiento y la elección que ella ha hecho de la naturaleza, en este caso no estrictamente por la marginación de las mujeres, sino por la falsedad e hipocresía que dicho mun- 
do representa; dice ahora la voz poética: “¿Todas las madres son tan cariñosas / entre esa gente de la raza humana? [...] ¿Las vidas de los hombres generosas / conságranse a la patria soberana? / ¿O entre brutos a súbditos y reyes / su instinto vale más que nuestras leyes?" (Coronado, 1991, p. 525). El cuestionamiento a la sociedad y el elogio de la naturaleza terminan valorizando la propia elección del sujeto lírico: no es necesario tener "ciencia elevada", para "cantar del campo embelesada / las risueñas perfectas hermosuras" / basta de mi garganta el leve acento, / y sobra tu magnífico talento" (Coronado, 1991, p. 525).

Coronado deja así a Avellaneda, simbolizada en la paloma, la sociedad, el triunfo, la altura, mientras continúa reivindicando su propia elección: la naturaleza, el campo, que suponen otro tipo de éxito o de reconocimiento, que la escritora expresa en un interesante oxímoron, "la gloria campesina". Es, así, la "gloria campesina" y no otra, la que, como alondra, ave que utiliza ahora como símbolo para sí misma, quiere. Aunque no deja de desear, por último, a Avellaneda, el mayor éxito en el camino escogido, ubicándola asimismo en el lugar de la "mujer regenerada", nuevo tipo de mujer, esa que va a representar los valores positivos dentro de esa sociedad constituida por una especie humana y/o femenina (hay una ambivalencia en el texto en este sentido, y cabe interpretar ambas posibilidades) degradadas:

$$
\begin{aligned}
& \text { Deja que mis estériles canciones } \\
& \text { mueran sobre este arroyo cristalino } \\
& \text { y sigue tú, paloma, este camino } \\
& \text { el vuelo remontando a otras regiones [...] } \\
& \text { Déjame a mí la gloria campesina, } \\
& \text { brille en la sociedad tu bella ciencia } \\
& \text { que allí a gloria mayor la providencia } \\
& \text { tu corazón y tu saber destinas: } \\
& \text { ipalpitante lección, viva doctrina } \\
& \text { a la ignorancia y femenil demencia! } \\
& \text { Serás, entre su especie degradada, } \\
& \text { tipo de la mujer regenerada. } \\
& \text { (Coronado, 1991, pp. 523-526). }
\end{aligned}
$$

En el poema se aprecia nítidamente la admiración, indudable, hacia Avellaneda, el reconocimiento de su talento y valía y el respeto que inspira a Coronado el camino que Avellaneda ha elegido. Pero hay también en el texto una distancia que se subraya y acentúa. La voz poética enuncia explícitamente la posibilidad de una elección otra, la suya propia, completamente contraria a la de Avellaneda: naturaleza frente a sociedad, "gloria campesina" frente a gloria a secas. Aunque parece muy elaborada individualmente, aunque pueda verse incluso en esa elección otra un germen de las reivindicaciones que hará el llamado feminismo de la diferencia, no deja de ser, a pesar de todo, la de Coronado, aquella elección que le ha sido asignada como mujer de acuerdo a los patrones de la sociedad en la que vive: la naturaleza. Como mismo recomendaba en sus artículos a las demás poetisas que no siguieran el modelo de Avellaneda, también en su poesía Coronado deja patente que tampoco ella elige ese modelo para sí misma.

Aunque no está dedicado a Avellaneda, me parece interesante el acercamiento a un poema más de Coronado, que creo nos permite entender mejor cuál es verdaderamente esa elección otra que se contrapone a la de Avellaneda y el porqué de la misma; me refiero al poema "En el castillo de Salvatierra", fechado en 1849; texto que creo complementario a "Yo no puedo seguirte con mi vuelo" y que podría considerarse incluso, en cierto modo, un homenaje indirecto e involuntario a Avellaneda. Lo que narra este poema es lo que ocurre al sujeto lírico cuando intenta asumir una elección que se corresponde con un modelo femenino que se revela muy cercano al avellanedino. Así, me parece sintomático que en "En el castillo de Salvatierra", el sujeto lírico recurra y elija la altura, es decir, el mismo elemento con el que antes se había identificado a Avellaneda, para reivindicar "para la poeta mujer el escenario desde el que los poetas románticos [...] habían emprendido sus meditaciones sobre el universo, la historia, y el yo" (Kirkpatrick, 1991, p. 220); en el texto, la altura va a ser fundamental, signo de la mayor libertad creativa y vital; como escribe Kirkpatrick, la mujer necesita también, como los hombres, "una altura desde la que observar el mundo" (Kirkpatrick, 1991, p. 220). El poema constituye una denuncia explícita de la opresión social de las mujeres en diversas épocas de la historia de España. El sujeto lírico del texto sube a la torre del castillo medieval de Salvatierra y desde allí alza su voz y formula su queja y su denuncia sobre la situación de las mujeres: "ni un eslabón los siglos quebrantaron / a nuestra anciana y bárbara cadena" (Coronado, 1991, p. 353). La altura parece darle fuerza, valor: "Por cima de las nubes nos hallamos, / ilibertad en el cielo proclamemos! / Las mismas nubes con los pies hollamos, / las alas en los cielos extendemos". (Coronado, 1991, p. 355); esta altura es aquí signo de aquella que ha conseguido imponerse por encima de las limitaciones que sufre como mujer y está dispuesta a afrontar la soledad que acompaña su elección: "Yo 
he triunfado del mundo en que gemía, / yo he venido a la altura a vivir sola" (Coronado, 1991, p. 355). El final del poema supone, sin embargo, el fracaso de la elección asumida: la torre se derrumba con la tormenta y el rayo; el firmamento, antes tan cercano, se aleja, y el sujeto lírico femenino, hasta entonces bien seguro de sí mismo, se siente débil y acaba acudiendo a Dios a pedir su ayuda para que la baje de la altura y la devuelva a la tierra: "iAy! isálvame, señor, porque ya creo / que le falta a mi orgullo fortaleza!" (Coronado, 1991, p. 356). Bajar de la altura, regresar a la tierra es, en este texto, signo de claudicación, de fracaso, de la imposibilidad femenina para asumir la elección de la trascendencia, la cultura, la gloria a secas. Como escribía Coronado en sus artículos, eran pocas las mujeres que, como Avellaneda, estuvieran dispuestas a pagar el precio de su libertad, de subir a la altura, de intentar conquistar esos mundos reservados a los hombres; así, la propia voz poética, que al principio de este poema parecía creer que podía, descubre al final del texto que ella tampoco puede: "que yo las nubes resistir no puedo" (Coronado, 1991, p. 355)2: la torre es demasiado oscura, la soledad demasiado grande, los rayos acaban llegando demasiado cerca; el "no poder", que en "Yo no puedo seguirte con mi vuelo" había sido convertido en logro, en triunfo otro, se convierte aquí en signo de derrota y desamparo, apareciendo sin adorno o racionalización alguna, en su total literalidad y desnudez; como lo expresan los impresionantes versos dirigidos a Dios con que se cierra el poema, que recuerdan, curiosamente, el verso final de "Amor de ciudad grande", de José Marti

\section{¡Bájame con tus brazos de la altura \\ que yo las nubes resistir no puedo! \\ ¡Sácame de esta torre tan oscura \\ porque estoy aquí sola y... tengo miedo! \\ (Coronado, 1991, p. 356).}

\section{CUBA Y LUISA PÉREZ}

No se conoce que Luisa Pérez haya respondido directamente en ningún escrito, como Coronado a Ferrer, al artículo de José Martí. Hay que decir que Luisa Pérez de Zambrana, que con ese nombre fue conocida la escritora, había perdido a su esposo Ramón Zambrana en 1866, un año antes de publicar la primera versión del excelente poema "La vuelta al bosque", al que se refiere Martí en su reseña, y es también en esa época madre de seis hijos que han quedado huérfanos. Sus circunstancias en 1875 son precarias, pues apenas posee recursos económicos; a estas circuns- tancias habría que añadir que en esos años en Cuba se desarrolla la primera guerra de independencia, la llamada Guerra de los Diez Años (1868-1878). No hay, en fin, hasta donde se conoce, una respuesta escrita de Luisa Pérez a las palabras martianas. Su respuesta es un acto, una conducta.

Hay que decir que la frase martiana no solo resulta sexista y anuladora respecto a Avellaneda: constituye también un condicionante poderoso para la poesía de la propia Luisa Pérez o, para decirlo con mayor exactitud, es quizás un reforzamiento del modo en que debe escribir. Pero la frase supone una lápida puesta no solo sobre la obra de Luisa Pérez, obligada a ser femenina, tierna y suave $\mathrm{s}^{4}$ sino, lo que es acaso más grave, sobre la mujer Luisa Pérez quien, a diferencia de Avellaneda, estaba viva en el momento en que Martí escribe su artículo. Quizás no sea muy probable que una mujer como Luisa Pérez, que había asumido estrictamente los valores normativos de su sociedad respecto a la mujer ${ }^{5}$, hubiera vuelto a casarse después de la muerte de su marido Zambrana, pero si alguna posibilidad hubo de que algo así ocurriera, la lapidaria (nunca mejor dicho) frase de Martí se habría encargado de evitarlo: "Mujer de un hombre ilustre, Luisa Pérez entiende que el matrimonio con el esposo muerto dura tanto como la vida de la esposa fiel" (Martí, $1875 / 1977$, p. 135). La frase ha sido interpretada por la crítica cubana como la constatación de un hecho porque, efectivamente, lo que se describe se cumplió. Sin embargo, se ha olvidado que en el momento en que Martí la escribe Luisa Pérez no había cumplido aún cuarenta años y llevaba apenas ocho de viudez. Pero Martí escribe "entiende", sin acompañarlo siquiera de un "parece". Se trata, para él, de un hecho dado en un presente eterno, que no termina. En realidad, más que constatar un hecho, la frase inscribe una especie de mandato. ¿Y qué poetisa del XIX se habría atrevido a desobedecer un mandato como este que la convertía, siempre que lo cumpliera, en el símbolo de las poetisas de América? ${ }^{6}$ Quizás Avellaneda hubiera osado desafiarlo, pero Luisa Pérez no era ella. La vida de Luisa Pérez duró mucho, casi 90 años, desde 1835 hasta 1922; sobrevivió a su ilustre marido cincuenta y seis años y murió siendo su viuda, y prácticamente en la miseria. En España se le conoce poco; en el resto de América, a excepción de Cuba y a pesar de la predicción de Martí, también.

Tal como ocurre con Carolina Coronado, hay constancia de la admiración que Luisa Pérez tuvo hacia Gertrudis Gómez de Avellaneda, a pesar de que Luisa Pérez asumiera estrictamente, sobre todo después de 
su matrimonio con Ramón Zambrana, los valores del "ángel del hogar". Fue precisamente Luisa Pérez la encargada de coronar a la autora de Sab a su regreso a Cuba en 1859 y sería Gómez de Avellaneda quien prologaría la segunda edición de la poesía de Pérez publicada en La Habana en 1860. Con motivo del regreso a Cuba, Luisa Pérez escribe su poema "A Gertrudis Gómez de Avellaneda", un texto que guarda concomitancias con el que le dedicara Carolina Coronado. Las dos primeras estrofas del poema recogen ese regreso a Cuba de Avellaneda que acaba de producirse. Como Coronado, Pérez emplea también la metáfora del vuelo calificado como "majestuoso", y que se refiere en el texto tanto al movimiento, al cambio de lugar de la escritora, como a la altura que esta ha alcanzado con su talento y su éxito; otra imagen que continúa poniendo de manifiesto la admiración hacia Avellaneda es la de "astro deslumbrador", que también es utilizada para describirla; así como el decir, mediante un elogio sin duda excesivo, pero que sigue mostrando el entusiasmo de la voz poética, que el siglo la considera "su primer poeta", y lo dice en masculino, o más exactamente, utilizando el genérico, pues en las siguientes estrofas podemos leer que Pérez no adopta la posición de la masculinización de la escritora, sino que intenta resaltar su valía, su talento, no solo entre las mujeres, sino entre todos los poetas, independientemente de su sexo. También se advierte la intensidad del deseo de la autora en torno al regreso de Avellaneda, que parece delatar esa reiteración de los "por fin" o "al fin", abundantes en estas primeras estrofas. Hay otro elemento que llama la atención, y es una especie de zona de sombra, de blanco, en torno a la vida de Avellaneda en España, esa vida anterior, previa a su vuelta a la isla, vida de la que poco parece saberse: en el poema Avellaneda aparece de pronto en Cuba, como en una historia contada in media res cuyos datos previos apenas se conocen, excepto el éxito de su obra. Siguiendo esta idea, sería posible proponer una particular escansión de los versos que forman ambas estrofas, que nos permite advertir esas zonas en blanco: "alzaste el vuelo... y te vemos llegar", "y por fin... apareces... en nuestro cielo". Veamos las estrofas mencionadas:

$$
\begin{aligned}
& \text { Por fin alzaste el vuelo majestuoso } \\
& \text { en un rapto de amor de tu alma inquieta, } \\
& \text { y te vemos llegar cuando orgulloso } \\
& \text { te aclama el siglo su primer poeta. } \\
& \text { Vuelves a Cuba, en fin, que tantas veces } \\
& \text { lloró tu ausencia con acerbo duelo, } \\
& \text { y por fin, más espléndido apareces }
\end{aligned}
$$

iastro deslumbrador! en nuestro cielo.

(Pérez de Zambrana, 1920, p. 70).

Más adelante, el poema comienza a enumerar las obras de la escritora que le han proporcionado el reconocimiento y el éxito y menciona, ante todo, su teatro, a través de títulos publicados y estrenados, como Egilona, Saúl, Alfonso Munio, Baltasar, el Príncipe de Viana - Recaredo. Aparece, después del teatro, la referencia al éxito en la poesía y se alude a esos años de juventud de Avellaneda en Cuba, donde ella habría comenzado, "virgen", "tímida", a dar sus primeros pasos en torno a la lírica, hasta poder dar "a la española poesía", "tanta grandeza y tanto brillo" (Pérez de Zambrana, 1920, p. 71). Se describe después, de modo hiperbólico, un estado de admiración general de la isla hacia la escritora, admiración que incluye a los hombres, a las mujeres y a los propios elementos de la naturaleza cubana: árboles, pájaros y aún al sol. En estas estrofas se mezcla el elogio a la escritora con el elogio a la naturaleza de la isla. Acaso donde más logrado aparece este propósito sea en la referencia al sol, donde Luisa Pérez establece una intertextualidad con el poema de Avellaneda titulado "Al sol en un día de diciembre". En aquel poema Avellaneda reclamaba la presencia del sol en medio del invierno ("El hielo caiga a tu fulgor deshecho; / iSal! Del invierno rígido a despecho") mientras se hacía evidente su nostalgia de Cuba y del clima del trópico ("Bajo otro cielo, en otra tierra lloro... / Donde la niebla abrúmame importuna... / ¡Sal rompiéndola, Sol, que yo te imploro!", Avellaneda, 1850, p. 927). Jugando con estos versos de Avellaneda, Luisa Pérez hace al sol "pararse", detenerse; un sol que viene, como sol del trópico, a alumbrar y calentar a la escritora pero también a mostrar su orgullo por sus éxitos y a homenajearla: "Y radiante de orgullo y de alegría / Verás al sol con fúlgida belleza, / Pararse en el ardiente mediodía / Para ceñir de rayos tu cabeza". (Pérez de Zambrana, 1920, p. 72). El poema termina con unos versos en los que vuelve a hacerse alusión a la altura de la escritora: ella debe bajar desde la altura y el triunfo europeos a su patria, a la tierra y la naturaleza cubanas; también allí va a encontrar, como en aquella, homenaje, tributo: “iOh baja, egregia y celestial cantora / del que Europa te alzó brillante solio / que hallarás en la patria que te adora / Ofrendas, pedestal y Capitolio". (Pérez de Zambrana, 1920, pp. 70-72).

No es este, sin embargo, el único poema de Luisa Pérez que cabe relacionar con Avellaneda. Voy a recurrir también a otro texto; en este caso, no un poema posterior, sino anterior a este; un poema escrito por Luisa Pérez en plena juventud y antes de casarse con 
Ramón Zambrana. El poema se titula "Contestación", está fechado en 1855 y solo fue incluido en la primera edición de la poesía de la escritora (1856), desapareciendo en las dos ediciones posteriores que publicó en vida y ya casada (1860 y 1920). “Contestación” es un poema-réplica que, en principio, podríamos relacionar con esos textos reivindicativos que pueden hallarse en cierta literatura escrita por mujeres y que se han convertido prácticamente en un género (Rodríguez Gutiérrez, 2011, p. 16), desde las redondillas de Sor Juana, pasando por "El porqué de la inconstancia", de la propia Avellaneda, o "Tú me quieres blanca", de Alfonsina Storni ${ }^{8}$. Aunque el poema-réplica de Pérez es diferente a estos; si aquellos poemas responden con energía a un discurso masculino discriminatorio o que minusvalora a la mujer, el de Pérez responde, llamativamente, a un discurso masculino positivo. Por ese y otros motivos, "Contestación" no se ubicaría claramente dentro de los poemas-réplica, pues no aparece en él, como en los textos mencionados, una crítica explícita a la situación de la mujer o una respuesta reivindicativa ante un discurso negativo en torno a la feminidad. Este texto estaría acaso más cerca de esas que Josefina Ludmer ha denominado, al analizar las estrategias empleadas en la Carta a Sor Filotea de Sor Juana Inés de la Cruz, como las "tretas del débil", aunque quizás podríamos decir, con mayor precisión, que lo que en este poema aparece es una incipiente "treta del débil”, pues Luisa Pérez no llega, como Sor Juana al decir de Ludmer, a cambiar el sentido del lugar que le ha sido asignado como mujer (Ludmer, 1985, p. 53); pero sí puede leerse en el texto de Pérez una denuncia de la situación subalterna de la mujer, expuesta, como en la carta a Sor Filotea, de modo indirecto, colocándose el sujeto lírico femenino en el papel de víctima. Al decir de Susana Montero, se trata del texto de Pérez en que la conciencia de género alcanza el punto más crítico (Montero, 2003, p. 72). El poema hace patente desde el inicio que se está respondiendo a la "invitación" de un "respetable amigo", que parece haber exhortado a la voz poética a que estudie y se "eleve / en alas de la hermosa poesía". Vemos nuevamente en este texto el protagonismo que adquiere la altura, que representa una vez más el ámbito de la libertad creativa y vital. Desde el comienzo, el sujeto lírico muestra también la imposibilidad para realizar ese que se va revelando, sin embargo, a lo largo del poema, como un intenso deseo; deseo que, por su condición de mujer, no puede satisfacer; impotencia que se expresa mediante ese verso que se va reiterando a lo largo del texto: "mujer, huérfana y joven nada puedo". Veamos el comienzo del poema:

\author{
Y tú me dices, respetable amigo, \\ que me entregue al estudio noche y día, \\ que abra espacio a mi mente, que me eleve \\ en alas de la hermosa poesía \\ a la etérea región, que abrace avara \\ la escena de los tiempos, que incansable \\ enaltezca mi ardiente fantasía \\ con objetos sublimes; que depure \\ mi gusto y surque los inmensos mares, \\ y abriendo mi alma a grandes impresiones \\ osada pise en extranjeros lares? [...] \\ ¿no te acordaste \\ al invitarme a recorrer naciones, \\ que en el mundo implacable y malicioso \\ mujer, huérfana y joven nada puedo? \\ (Pérez de Zambrana, 1957, p. 69).
}

Al final de estas dos estrofas, aparece un nuevo elemento y un nuevo deseo que va a cobrar mayor fuerza y protagonismo en la tercera; es el deseo del viaje, de "surcar los inmensos mares", "recorrer naciones". Resulta interesante advertir cómo este deseo que supone también "volar", representa en el texto tanto la ansiada altura de la creación como la anhelada altura vital, como si ambos se condensaran en uno. Asimismo, en estos versos "puede advertirse la gravitación del poema 'Al partir' de Gertrudis Gómez de Avellaneda" (Rodríguez Gutiérrez, 2011, p. 116), en esa descripción imaginada de los movimientos que va realizando la nave dispuesta a partir, tal como ocurre en el célebre soneto de Avellaneda. Con la diferencia de que Avellaneda describe el buque en que ella está realmente partiendo de la isla ${ }^{9}$, mientras Pérez embarca en una nave que solo zarpa, embriagante, en su imaginación:

¡Oh y si supieras como mi alma ardiente de emoción palpitante se recrea con la embriagante y seductora idea de ver abrirse las turgentes velas, flotar el lino, levantarse el ancla, crujir la quilla y como el viento raudo volar meciéndose el bajel sereno sobre la azul inmensidad...! ¡Dios mío! ¡Qué suprema ventura! y yo no puedo tanta dicha gozar...! oh! cuál extingue, cuál consume mi vida ese deseo eterno, ardiente, inextinguible...! oh cielo! (Pérez de Zambrana, 1957, p. 69). 
Los versos siguientes dan muestra de la intensidad del deseo y de la confusión y ambivalencia de la voz poética que pide deshacerse de la que considera una ilusión "irrealizable y loca", una "idea tenaz que me arrebata / la dulce paz que disfrutar ansío!" (Pérez de Zambrana, 70).

Más adelante aparece la crítica más dura contenida en el texto, en la que se denuncia la situación de la mujer, comparada con la del esclavo, tal como había hecho también Avellaneda en su novela Sab, publicada en Madrid en 1841 y cuya edición fue prohibida en Cuba:

Con lástima me miras... te comprendo..

Te inspiro compasión... pues bien, ¿̇lo sabes?

yo no puedo ser nada, soy esclava

como mujer al fin, y el cuello doblo

al yugo fuerte que nos priva injusto

de la adorable libertad que el hombre

goza feliz en su extensión entera. [...]

(Pérez de Zambrana, 1957, p. 70).

El poema termina con la total renuncia de la voz poética a esta noble invitación de su amigo, reiterando lo imposible de su deseo por su condición de mujer, unida a su orfandad y juventud:

Mi buen amigo,

ya sabes cuánto se me opone, y cuánto

yo lucho por vencer...! oh! no te ofendas

si a tu afectuosa invitación no cedo,

pues tú bien sabes que en el mundo injusto

mujer, huérfana y joven nada puedo.

(Pérez de Zambrana, 1957, 70).

Creo que no resulta forzado decir que "Contestación" puede considerarse el equivalente a "En el castillo de Salvatierra" de Carolina Coronado. Como en aquel, se plantea también en este texto una dura denuncia de la situación de la mujer. Por otra parte, aunque quizás con menos fuerza pues desde el principio aparece como imposible, hallamos un propósito de conquista de la libertad, de sus altas regiones creativas y vitales, y una vez más, esa imagen de la altura vuelve a acompañarnos. Tal como el sujeto lírico de "En el castillo de Salvatierra" terminaba bajando de la torre, aquí la voz poética renuncia a la invitación del amigo a estudiar, a viajar, a abrazar "la escena de los tiempos". El resultado, entonces, vuelve a ser la imposibilidad, la impotencia declarada y la renuncia.

\section{CONCLUSIÓN: DE LA ATURA A LA ALTIVEZ, O ELABO- RACIONES FEMENINAS Y METONIMIAS MASCULINAS}

Las respuestas de Carolina Coronado y Luisa Pérez en la polémica en torno al género en Avellaneda aportan datos relevantes y bien sugerentes. Es obvio que ninguna de las dos poetisas se decidió a seguir el modelo presuntamente masculino de Avellaneda y que ambas intentaron distanciarse del mismo, en la vida y en la escritura. Coronado respondió explícitamente, aunque con ambigüedad, al debate, con artículos donde reivindicó la condición femenina de Avellaneda y apuntó sagaces argumentos para explicar su masculinización por parte de la crítica: su enorme éxito en la poesía y fundamentalmente como autora teatral; aunque también recomendó a las escritoras no seguir el modelo que ella ofrecía por el alto coste vital que suponía. Luisa Pérez, por su parte, respondió sin responder, con un acto, una conducta, en los que es posible leer su obediencia a la letra y al mandato de José Martín ${ }^{10}$.

Pero quizás lo más interesante sean las respuestas indirectas que encontramos en la escritura poética de Coronado y Pérez. En los textos de ambas no solo hay notables testimonios de la gran admiración hacia Avellaneda, sino también evidentes signos de que las dos poetisas se sintieron en algún momento de sus vidas fuertemente atraídas por ese modelo que representaba la poeta; modelo que, al contrario de la crítica masculina, ellas no leyeron como signo de masculinización, altivez o soberbia, sino como símbolo de la mujer que se atreve a asumir y a defender su libertad creativa y vital. Poemas como "En el castillo de Salvatierra" y "Contestación" muestran asimismo que la renuncia a encarnar dicho modelo no fue una decisión libre y espontánea para las poetisas, sino una resolución tomada a posteriori, como consecuencia de la toma de conciencia sobre las limitaciones que padecía la mujer en la sociedad; resolución que supone entonces una dosis de sufrimiento y un taponar del deseo; un signo, en fin, de impotencia, de falta de fortaleza, de derrota. En los textos examinados de Coronado y Pérez hallamos diversos elementos comunes. Uno de ellos, presente en los dos poemas de homenaje explícito a Avellaneda, es la elección, más directa en Coronado, más indirecta en Pérez, que se hace de la naturaleza, frente a la sociedad o a Europa, elegidas por Avellaneda. Pero acaso el elemento más significativo es la referencia a la altura, que aparece en los cuatro poemas comentados; la altura es la más clara representación de Avellaneda en los dos poemas dedicados a ella. En los dos poemas de homenaje explícito, Avellaneda aparece muy alta y prácticamente 
inaccesible: el yo poético en el poema de Coronado no consigue alcanzarla, aunque lo intenta; el del poema de Pérez ni siquiera se lo propone; de algún modo, para poder encontrarse con ella, una y otra necesitan que Avellaneda "baje": bien sea a la naturaleza o a la isla de Cuba. En estos textos de homenaje la altura tiene también otras connotaciones: denota la lejanía en que está colocada Avellaneda para ambas autoras, lejanía que viene dada, por supuesto, por sus grandes éxitos como escritora, que tanto Coronado como Pérez sienten como imposibles de alcanzar; pero que remite también, de algún modo, a la particular condición identitaria de Avellaneda, que la hace, en cierto modo, inatrapable: los poemas producen cierto enigma en torno a la figura de Avellaneda; en ambos textos hay algo de ella que escapa; en los dos, ella viene de un sitio que resulta desconocido tanto para Coronado como para Pérez. En el poema de Coronado, se alude vagamente a esta circunstancia (la "paloma" frente a la "tortuga perezosa", el "vuelo" que no se puede seguir), pero en el de Pérez esa identidad en movimiento de Avellaneda queda mucho más explícita: ella vuelve, regresa, después de haber estado en ese lugar que Pérez nunca ha visto: Europa; "te vemos llegar", dice Pérez al comienzo del poema, lo que nos sugiere un otro lado de Avellaneda, su lado español y europeo, que permanece oculto, invisible e inaccesible, para Pérez y para los cubanos de la isla.

Sintomáticamente, en los otros dos textos, esos en los que se reflexiona en torno al deseo de libertad y se denuncia la propia condición y la situación de la mujer, viene también la altura a significar el deseo de elevación literaria y vital. Caer, bajar, renunciar a ella, se convierte en signo de derrota, de renuncia impuesta por las circunstancias que se sufre como mujer.
Solo una reflexión final: uno de los términos que se repite de Ferrer del Río a Martí es precisamente la referencia a la altura de Avellaneda, solo que Ferrer del Río y Martí han efectuado diversas metonimias o desplazamientos sobre el término, metamorfoséandolo en otra cosa: la "altura" se ha transformado en "altivez" (y en sinónimos como "soberbia"); el término va cobrando, además, mayor virulencia: lo que en Ferrer del Río es "carácter altivo" se ha convertido, en Martí, en "hombre altivo". Las metonimias y desplazamientos consiguen así significar lo contrario: empequeñecer a la escritora, disminuirla. Al leer a Ferrer del Río y a Martí junto a Coronado y a Pérez, hallamos, sin embargo, que en esos términos pervive, como en esos actos fallidos que siguen diciendo lo que no se quería, ese que podríamos nombrar como el significante primario, sobre el que se llevó a cabo la transformación, ese significante insoportable para la crítica masculina de la época: la altura, literaria y vital, de Gertrudis Gómez de Avellaneda. Cabe, acaso, terminar recordando la protesta de Virginia Woolf: "No hay ninguna marca en la pared que mida la altura exacta de las mujeres" (Woolf, 1929/1997, p. 117), o unas palabras suyas más críticas y explícitas: "[...] tanto Napoleón como Mussolini insisten [...] marcadamente en la inferioridad de las mujeres, ya que si ellas no fueran inferiores, ellos cesarían de agrandarse" (Woolf, 1929/1997, p. 51).

\section{AGRADECIMIENTOS}

Este artículo se inserta dentro del trabajo del Proyecto de Investigación "Las poetas hispanoamericanas: identidades, feminismos, poéticas (S. XIX-XXI)" (FEM 2013-42041P), financiado por el Ministerio de Economía y Competitividad.

\section{NOTAS}

1 En este sentido, cabe apuntar que en el ya mencionado prólogo a la primera edición de 1841 de la poesía de Gertrudis Gómez de Avellaneda, Juan Nicasio Gallego, después de referirse al canto "varonil" de la autora, intenta, sin duda, suavizar o matizar sus palabras cuando añade: "Sin embargo, sabe ser afectuosa cuando quiere" (Gómez de Avellaneda, 1841, p. IX) y enumera poemas que lo testimonian, para concluir afirmando la "flexibilidad de su talento" (Gómez de Avellaneda, 1841, p. IX), argumento, este último, que resulta similar al que expone Coronado en su defensa de Avellaneda. Habría que recordar que en estas fechas la escritora no ha publicado aún ninguna de sus obras de teatro; solo se ha puesto en escena la primera, Leoncia (1840).

2 Discrepo del punto de vista de Kirkpatrick cuando considera que con los versos finales "Coronado adopta la perspectiva de los críticos paternalistas como Hartzenbusch y Deville y trata la aspiración a una libertad sublime de la imaginación y a un espíritu creativo -considerados como admirables en el yo romántico masculino- como insostenibles para el yo femenino" (Kirkpatrick, 1991, p. 222). En mi opinión, Coronado no adopta la perspectiva de los críticos paternalistas; muestra, trágicamente, su miedo humano y su debilidad individual como sujeto femenino para llevar hasta sus últimas consecuencias su deseo reivindicativo de liberación.

3 En "Amor de ciudad grande", texto que se ubica en Nueva York, Martí cuestiona la ciudad y el amor que en ella se vive, amor "de gorja" y "rapidez", "sin pompa ni misterio"; y termina dejando a los "catadores ruines" esos "vinillos humanos", que él rechaza con esta frase: "Tomad! Yo soy honrado, y tengo miedo!"(Martí, 2001, pp. 125-128). El miedo de Martí 
supone superioridad moral; es un miedo interior, a sí mismo; el de Coronado, al contrario, denota debilidad para asumir una elección que ya se ha hecho y que se considera correcta y necesaria; más que interior, su miedo es hacia el afuera: la tormenta, el trueno, es decir, hacia la sociedad y su abandono.

4 Al revisar la tradición poética femenina cubana, se advierte que el juicio de Martí ha condicionado las valoraciones de ambas escritoras a lo largo del siglo XIX y aun del XX. Susana Montero señala que se trata de una oposición que con Martí queda "definitivamente asentada" (Montero, 2003, p. 71); Madeline Cámara califica el juicio martiano como "devastadora influencia" (Cámara, 1998, p. 145). Sobre Luisa Pérez, escribía por ejemplo Enrique José Varona en el prólogo a la edición de su Poesía de 1920: “Jamás la poesía castellana ha encontrado notas más suaves, más dulces, más tiernas para trasladar los afectos de un alma férvida". (Pérez de Zambrana, 1920, p. 6).

5 Sobre la vida y la obra de Luisa Pérez de Zambrana puede verse el reciente estudio de Félix Ernesto Chávez López (2014).

\section{BIBUIOGRAFÍA}

Cámara, M. (1998). Visiones de la mujer en la obra de José Martí: discusión de su influencia. En: Aragón, U. (ed.). Repensando a Martí. Salamanca: Universidad Pontificia de Salamanca, pp. 145-153.

Chávez López, F. E. (2014). La claridad en el abismo. La construcción del sujeto romántico en Luisa Pérez de Zambrana. Madrid: Verbum.

Coronado, C. (1861a). Galería de poetisas contemporáneas. Doña Gertrudis Gómez de Avellaneda. La América. Crónica hispano-americana, 2, pp. 10-11.

Coronado, C. (1861b). Galería de poetisas contemporáneas. Doña Gertrudis Gómez de Avellaneda [II]. La América. Crónica hispano-americana, 3, pp. 9-10.

Coronado, C. (1991). Poesías. Madrid: Castalia / Instituto de la Mujer.

Fernández Daza Álvarez, C. (2012). «Yo no puedo seguirte con mi vuelo». En Actas de las III Jornadas de Almendralejo
6 Es probable que cuando considera a Luisa Pérez como símbolo de las poetisas americanas, Martí esté pensando también en el poema "Adiós a Cuba", que Luisa Pérez escribiera con motivo de su partida de Santiago de Cuba hacia La Habana y que publicara en la primera edición de su poesía de 1856; poema que fue cantado por los mambises durante la Guerra de los Diez Años, convertido en especie de himno de lucha; dice la última estrofa del poema: " $\mathrm{iOh}$ Cuba! si en mi pecho se apagara / tan sagrada ternura y olvidara / esta historia de amor, / hasta el don de sentir me negaría / pues quien no ama la patria ¡oh Cuba mía! / no tiene corazón" (Pérez de Zambrana, 1920, p. 14).

7 La primera versión de este poema apareció por primera vez en libro en la edición de 1841, con algunas variantes; el título es "Al sol en un día del mes de diciembre" y el último verso dice: “ $\mathrm{iEl}$ invierno me mata!... iyo te imploro!" (Avellaneda, 1841, p. 170); también varía la fecha que encontramos al final; en 1841 se lee: "1839"; mientras en 1850 dice: "Diciembre de 1840".

8 Puede hallarse un análisis de este poema de Avellaneda en mi artículo "Filo-

y Tierra de Barros. Almendralejo: Asociación Histórica de Almendralejo, pp. 271-292.

Ferrer del Río, A. (1846). Galería de la literatura española. Madrid: Establecimiento tipográfico de D. F. de P. Mellado.

Girona, Nuria (2011). Rituales de la verdad. Mujeres y discursos en América Latina. París: ADHL.

Gómez de Avellaneda, G. (1841). Poesías de la señorita Gertrudis Gómez de Avellaneda. Madrid: Establecimiento Tipográfico.

Gómez de Avellaneda, G. (1850). Poesías de la excelentísima señora Da. Gertrudis Gómez de Avellaneda de Sabater. Madrid: Imprenta de Delgrás Hermanos.

Kirkpatrick, S. (1991). Las Románticas. Escritoras y subjetividad en España, 1835 1850. Madrid / Universidad de Valencia: Cátedra / Instituto de Estudios de la Mujer. sofía en el tocador. Poetas cubanas del XIX", incluido en Rodríguez Gutiérrez (2012, pp. 16-24). Por otra parte, en $\mathrm{mi}$ ensayo Lo que en verso he sentido. La poesía feminista de Alfonsina Storni aparece una interpretación del poema "Tú me quieres blanca" (Rodríguez Gutiérrez, 2007, pp. 97-109).

9 Un análisis del soneto "Al partir", donde se llama la atención sobre cómo aparecen en el poema los movimientos del barco puede encontrarse en mi artículo "Partir / marchar(se). EI NO femenino en la poesía cubana del XIX y del XX. Gertrudis Gómez de Avellaneda e Isel Rivero" (Rodríguez Gutiérrez, 2013).

10 Llamativamente Cintio Vitier nombró a Luisa Pérez de Zambrana como "la obediente", por esa actitud que, al decir de Vitier, la caracterizó, la de la obediencia humilde y entrañable a cuanto se fue ofreciendo ante sus ojos: la naturaleza, el amor, el dolor (Vitier, 1969, p. 46). Quizás la lectura que proponemos en este trabajo nos ofrezca, sin embargo, una dimensión otra, más cercana a lo siniestro freudiano, de la obediencia en Luisa Pérez.

Ludmer, J. (1985). Tretas del débil. En: González, P. E. y Ortega, E. (eds.). La sartén por el mango. Encuentro de escritoras latinoamericanas. Río Piedras: Huracán, pp. 47-54.

Martí, J. (1875/1977). Tres libros. Poetisas americanas. Carolyna Freire. Luisa Pérez. La Avellaneda. Las Mexicanas en el libro. Tarea aplazada. En: Luisa Pérez de Zambrana. Antología poética. La Habana: Arte y Literatura, pp. 134-138.

Martí, J. (2001). Ismaelillo. Versos libres. Versos sencillos. Madrid: Cátedra.

Montero, S. (2003). La cara oculta de la identidad nacional. Un análisis a la luz de la poesía romántica. Santiago de Cuba: Oriente.

Pérez de Zambrana, L. (1920). Poesías (Publicadas e inéditas). Habana: Imprenta El Siglo XX de la Sociedad Editorial Cuba Contemporánea.

Pérez de Zambrana, L. (1957). Poesías completas (1853-1918). La Habana: Im- 
prenta P. Fernández y Cía., colección Los Zambrana, Tomo XI.

Prado Más, M. (2001). El teatro de Gertrudis Gómez de Avellaneda [Tesis doctoral]. Madrid: Universidad Complutense de Madrid. Recuperado de http://eprints. ucm.es/tesis/fll/ucm-t25107.pdf

Pratt, M. L. (2003). La poética de la perversión: Poetisa inubicable devora a su maestro. No se sabe si se trata de aprendizaje o de venganza. En SmithWelle, F. (ed.). Ficciones y silencios fundacionales. Literaturas y culturas poscoloniales en América Latina (siglo $X I X)$. Madrid / Frankfurt am Main: Iberomericana / Vervuet, pp. 27-46.
Rodríguez Gutiérrez, M. (2007). Lo que en verso he sentido. La poesía feminista de Alfonsina Storni. Granada: Universidad de Granada.

Rodríguez Gutiérrez, M. (2011). Otra Cuba secreta. Antología de poetas cubanas del XIX y del XX. De Gertrudis Gómez de Avellaneda a Reina María Rodríguez, Madrid: Verbum.

Rodríguez Gutiérrez, M. (2012). Entre el cacharro doméstico y la Vía Láctea. Poetas cubanas e hispanoamericanas. Sevilla: Renacimiento.

Rodríguez Gutiérrez, M. (2013). “Partir / marchar(se). El NO femenino en la poe- sía cubana del XIX y del XX. Gertrudis Gómez de Avellaneda e Isel Rivero", La Habana Elegante, 53. Recuperado de http://www.habanaelegante.com/ Spring_Summer_2013/Dossier_Poetas_RodriguezGutierrez.html

Russotto, M. (1993). Tópicos de retórica femenina: memoria y pasión del género, Caracas: Monte Ávila.

Vitier, C. (1969). La obediente. En Poetas cubanos del siglo XIX: semblanzas. La Habana: Unión, pp. 44-46.

Woolf, V. (1929/1997). Una habitación propia. Barcelona: Seix Barral. 